\title{
A revelação do diagnóstico na perspectiva dos adolescentes vivendo com HIV/AIDS e seus pais e cuidadores
}

\author{
Disclosure of HIV infection from the perspective \\ of adolescents living with HIV/AIDS and their \\ parents and caregivers
}

\author{
1 Faculdade de Medicina, \\ Universidade de São Paulo, \\ São Paulo, Brasil. \\ 2 Programa Municipal \\ de DST/AIDS de Santos, \\ Santos, Brasil. \\ 3 Instituto de Infectologia \\ Emílio Ribas, \\ São Paulo, Brasil. \\ 4 Faculdade de Saúde \\ Pública, Universidade \\ de São Paulo, \\ São Paulo, Brasil. \\ 5 Centro de Referência \\ em DST/AIDS, Secretaria \\ de Estado da Saúde \\ de São Paulo, \\ São Paulo, Brasil. \\ 6 Instituto de Psicologia \\ Universidade de São Paulo, \\ São Paulo, Brasil. \\ Correspondência \\ H. H. S. Marques \\ Instituto da Criança, \\ Departamento de Pediatria \\ Faculdade de Medicina \\ Universidade de São Paulo. \\ Av. Dr. Enéas de Carvalho \\ Aguiar 647, São Paulo, SP \\ 05403-900, Brasil. \\ heloisahsm@icr.hcnet.usp.br
}

\section{Abstract}

The purpose of this study was to identify relevant issues in the disclosure of HIV-positive status in children and adolescents, aiming to improve the quality of their healthcare. A qualitative study included adolescents living with HIVI AIDS and their parents and caregivers at AIDS reference services in São Paulo and Santos, Brazil. In-depth interviews and focus group were used. The main reasons for disclosure were: poor treatment adherence, sexual maturity, adolescent's request, and inadequate procedures by medical staff. Disclosure was a critical moment for adolescents, with a strong impact on their life plans and horizons. Adolescents infected through sexual transmission and drug use reported the most problematic scenes involved in disclosure. Despite its initial negative impact, disclosure resulted in improved healthcare and better dialogue among the adolescents, caregivers, and healthcare providers. The adolescents also requested clear, no-nonsense, honest information. The authors conclude that health services need to actively provide an adequate approach to facilitate disclosure of HIV-positive status to children and adolescents, realizing that it is a long-term process supported by the family and a multidisciplinary team.

Adolescents; Acquired Immunodeficiency Syndrome; Clinical Diagnosis
Heloisa Helena de Sousa Marques 1

Neide Gravato da Silva 2

Pilar Lecussan Gutierrez 1

Regina Lacerda 2

José Ricardo Carvalho Mesquita Ayres 1

Marinella DellaNegra 3

Ivan França Jr. 4

Eliane Galano 5

Vera Paiva 6

Aluisio Augusto Cotrim Segurado 1

Mariliza Henrique da Silva 5

\section{Introdução}

Uma questão antiga e persistente em diversos ramos das práticas de saúde, diz respeito a como e quando contar a uma criança sobre uma doença que lhe afeta cronicamente, e a extensão dessas informações 1. Com a AIDS não tem sido diferente.

O número de crianças em idade escolar e adolescentes vivendo com HIV nos serviços é crescente, decorrência do aumento do tempo de sobrevida em função da evolução da terapia anti-retroviral e do manejo clínico geral, e do acesso universal a estes recursos nos serviços públicos de saúde 2,3. Este fato tem resultado em prescrição de esquemas terapêuticos complexos, que certamente requerem explicações detalhadas e uma adequada compreensão e adesão dos pacientes. Desse modo, o compartilhamento dessas informações com as crianças e adolescentes constitui, hoje, uma necessidade cada vez mais presente. Contudo, ainda há muitas crianças nos serviços de saúde que estão chegando à adolescência sem ter informações completas sobre sua história, ainda que a recomendação predominante na literatura seja o estabelecimento de um diálogo contínuo entre equipe de saúde, criança e família, de modo a aproximá-los progressivamente do momento da revelação 4,5,6. A esse grupo, acrescem-se aqueles que adquiriram a infecção já na adolescência, por outros modos de trans- 
missão, e que também vivenciam dificuldades no conhecimento de seu diagnóstico 7,8,9.

O objetivo do presente estudo foi identificar aspectos da revelação do diagnóstico da infecção pelo HIV a crianças e adolescentes, sob o ponto de vista de adolescentes vivendo com HIV/AIDS e seus cuidadores, procurando entender as dificuldades envolvidas e indicar estratégias para sua superação.

\section{Método}

Este estudo faz parte de um projeto de pesquisa integrado a uma iniciativa de cooperação internacional para melhoria do cuidado às pessoas vivendo com HIV/AIDS - Enhancing Care Iniciative (ECI) 10. A iniciativa é coordenada pelo Harvard Aids Institute e François Xavier Bagnoud Center for Health and Human Rights, Harvard School of Public Health. O ECI-Brasil iniciou em 2001 um estudo sobre a situação dos adolescentes soropositivos, população que foi aumentando significativamente nos últimos anos no Brasil, não apenas pela disseminação da epidemia, mas também pelos expressivos incrementos nos recursos terapêuticos e a bem sucedida política de acesso universal a esses recursos no Sistema Único de Saúde (SUS).

Foi realizado estudo qualitativo 11,12, com adolescentes de idade entre 10 e 20 anos (data de referência: 31 de dezembro de 2003), conhecedores de seu status sorológico, e com cuidadores (pais naturais, pais adotivos, parentes, responsáveis institucionais) de outros adolescentes na mesma condição, conhecedores ou não de sua soropositividade. Os participantes (adolescentes e cuidadores) foram selecionados de um total de 248 adolescentes elegíveis entre os usuários de cinco serviços de referência para o tratamento de HIV/AIDS nas cidades de São Paulo e Santos, Brasil - Casa da AIDS (CAIDS), Centro de Referência e Tratamento em HIV/AIDS (CRT/AIDS), Instituto de Infectologia Emílio Ribas (IIER) e Instituto da Criança (ICr), em São Paulo, e Centro de Referência em HIV/AIDS (CRAIDS) e Núcleo Integrado da Criança (NIC), em Santos.

Os participantes foram selecionados conforme perfis relevantes para o estudo proposto, combinando aspectos como idade do adolescente soropositivo, seu sexo, modo de infecção (vertical, transfusional, por uso de drogas injetáveis, sexual e indeterminada) e características do cuidador (além das modalidades acima descritas, o seu status sorológico, isto é, nãoinfectados, pais discordantes quando somente a mãe estava infectada e pais concordantes, ambos infectados).

Foram estabelecidos contatos com os potenciais participantes da pesquisa com base em seus agendamentos de rotina nos serviços participantes. Adolescentes e seus pais foram consultados sobre seu interesse e disponibilidade para participar, assim como sobre a capacidade física e mental para fazê-lo. Houve duas recusas de participação.

O número total de participantes não foi definido a priori, como usual em estudos qualitativos, sendo definidos ao longo do processo de pesquisa, segundo critério de suficiência, isto é, quando os pesquisadores julgaram que o material empírico já permitia traçar um quadro compreensivo da questão investigada. O desenho da investigação incluiu: entrevistas em profundidade, do tipo depoimento, tomando como informantes 22 adolescentes e 13 cuidadores, captados nas cinco instituições envolvidas. No NIC, em Santos, foram realizados três grupos focais com a participação de 11 cuidadores. Por fim, a pesquisa foi complementada por estudos de caso de três processos de revelação diagnóstica ocorridos no ICr, com base na participação direta de uma das pesquisadoras e em entrevistas com os cuidadores e adolescentes envolvidos.

As entrevistas e os grupos focais foram realizados, no período compreendido entre setembro de 2002 e março de 2003, pelos próprios pesquisadores responsáveis e auxiliares de campo supervisionados pela equipe de pesquisadores. As entrevistas em profundidade seguiram roteiro semi-estruturado, foram gravadas em fita cassete, posteriormente transcritas e realizadas em encontro único, com duração variando de quarenta minutos a duas horas. Para as entrevistas com cuidador foram utilizados quatro diferentes roteiros, segundo especificidades relacionadas ao seu perfil - grau de parentesco ou tutela, estado sorológico e modo de infecção do jovem de que cuida. Em relação aos adolescentes foi utilizado um roteiro único. Foram seis os principais eixos temáticos das entrevistas: (1) principais aspirações, planos e referências; (2) como viveram e avaliaram o processo de revelação do diagnóstico; (3) nível de conhecimento sobre saúde sexual, reprodutiva e prevenção do HIV; (4) auto percepção sobre os cuidados e acolhimento das suas necessidades pelos serviços; (5) como manejam no cotidiano as dificuldades; e (6) desafios do cuidado.

Os três grupos focais foram realizados com cuidadores convidados por meio de cartas e contato direto pelos profissionais da instituição. Aplicou-se um roteiro que abordava ques- 
tões sobre a revelação e suas dificuldades no contexto familiar: revelação do diagnóstico; quem deve revelar; o melhor momento para a revelação; quem deve conhecer o diagnóstico; percepções da criança ou adolescente (dependendo da idade da revelação) em relação ao seu diagnóstico.

No ICr buscou-se identificar, nos estudos de caso, as diversas motivações de pais, cuidadores e profissionais quanto à revelação do diagnóstico, aspectos considerados positivos e negativos e fatores facilitadores e dificultadores do processo.

Os conteúdos das entrevistas e grupos focais foram trabalhados como "discursos", isto é, os depoimentos foram tomados como unidades de sentido, interpretadas de modo nãoformalista, desde uma perspectiva hermenêutica 13. Buscou-se identificar eixos de significação em torno dos quais os discursos se organizaram, os fatos e ações a que se referiam concretamente e os valores, crenças e sentimentos associados a esses fatos e ações. Também é constitutivo da abordagem hermenêutica o pressuposto de que qualquer interpretação é indissociável de uma totalidade compreensiva e, por isso mesmo, que sua validade é profundamente dependente dos interesses práticos e do quadro teórico de referência dos intérpretes 14.

O quadro teórico que guiou o estudo foi construído com base no conceito de vulnerabilidade 15,16. O ponto de partida das análises de vulnerabilidade, seu componente individual, é sempre algum agravo à saúde, ou limitação, buscando-se identificar tão exaustivamente quanto possível os fatores físicos, mentais ou comportamentais que podem expor um indivíduo a tal agravo ou limitação. Uma vez que esses aspectos são levantados, por meio de analises de risco ou outras fontes de conhecimento biomédico, busca-se, no componente social, caracterizar as diferentes chances e maneiras da exposição ao agravo distribuir-se na população, compreendendo seus determinantes contextuais, isto é, os aspectos culturais, morais, políticos, econômicos e institucionais que possibilitam a exposição ou, ao contrário, a desfavorecem. Por fim, o componente programático busca examinar o papel exercido por políticas, programas e serviços na intervenção sobre os diversos contextos sociais e suas repercussões sobre a vulnerabilidade de populações e indivíduos. $\mathrm{O}$ interesse desse quadro conceitual decorre do fato de que, ao conduzir o raciocínio determinístico do nível individual/orgânico ao coletivo-social, e vice-versa, a análise de vulnerabilidade possibilita um diálogo muito objetivo entre as diferentes disciplinas e áreas técnicas envolvidas na saúde - fisiopatologia, microbiologia, epidemiologia, clínica, psicologia, sociologia, antropologia etc.

De outro lado, estudos recentes, especialmente na área de HIV/AIDS, têm demonstrado como a perspectiva dos direitos humanos têm oferecido uma referência clara e sólida não apenas para a identificação e compreensão de situações socialmente configuradas de vulnerabilidade, como também para identificar meios para ajudar a superar a situação 17,18,19 . Com efeito, os direitos humanos tornam mais visíveis as diferentes dimensões e padrões sobre os quais se fundam concretamente os ideais humanos de bem-estar social, moral, mental e físico - aqueles, portanto, a que cada grupo populacional ou indivíduo deve ter acesso.

A elaboração dos roteiros e a interpretação dos discursos foram orientadas por esse quadro compreensivo, com especial interesse em perceber de que modo os serviços e programas de saúde podem reduzir a vulnerabilidade de adolescentes vivendo com HIV/AIDS às conseqüências negativas de seu estado sorológico sobre seu bem-estar psicossocial, sobre o pleno gozo de seus direitos humanos. No presente artigo, focaremos especialmente a questão da revelação do diagnóstico, aspecto extremamente sensível nesse sentido.

O projeto foi aprovado pela Comissão de Ética para Análise de Projetos de Pesquisa (CAPPesq) do Hospital das Clínicas, Faculdade de Medicina, Universidade de São Paulo, e assim como o Termo de Consentimento Livre e Esclarecido em sessão de 12 de junho de 2002, com a designação de Protocolo de Pesquisa n. $357 / 2002$. Também foi submetido e aprovado nas demais instituições envolvidas no estudo.

\section{Resultados}

\section{Estudos de caso e grupos focais}

Em uma primeira fase do presente estudo foram analisadas criticamente as iniciativas que já estavam em curso acerca da revelação do diagnóstico em dois dos serviços participantes, o ICr e o NIC. Conforme referido acima, para a realização desta etapa, o NIC utilizou grupos focais com cuidadores e o ICr utilizou entrevistas com cuidadores e adolescentes.

Como resultado dessa experiência observou-se que as demandas para revelação do diagnóstico são geradas pela própria equipe, por familiares e por ambos. Foram identificados como elementos que dificultam a tarefa: o medo do preconceito, da discriminação e da 
reação da criança, e do que poderá acontecer após a revelação; o desconforto pela exposição da história familiar; e medo das responsabilidades. Em ambos os serviços, os pais e cuidadores quando foram inicialmente questionados acerca da possibilidade da revelação do diagnóstico ao jovem, julgaram-se "despreparados" para a revelação, solicitando apoio dos serviços para a tarefa. No NIC, os pais referiram que a revelação seria melhor se efetuada por eles próprios, evitando assim a eclosão de sentimentos de traição, enquanto no ICr os pais consideraram melhor que os profissionais fizessem a revelação, apesar de, na maioria das vezes, terem eles mesmos acabado por revelar.

A partir da análise das experiências em curso acima referidas, foram feitas as entrevistas em profundidade com os adolescentes (Tabela 1) e com os cuidadores (Tabela 2), cujos achados serão apresentados a seguir.

\section{Entrevistas com os adolescentes}

O primeiro aspecto a destacar nas falas dos adolescentes é um eixo estruturante reiteradamente encontrado nas entrevistas: a normalidade, o ser normal. Há evidente empenho em descrever-se como "um jovem normal". Essa normalidade é obstaculizada, no entanto, pela necessidade de se cuidar e cuidar do outro, e porque foram obrigados a encarar, mais cedo do que a maioria dos jovens, o fato de serem mortais e correrem risco de vida.

"Uma vida totalmente normal, entendeu? A gente tem que tomar cuidado é nos riscos, assim, de estar com machucado... não ficar passando, sabe, naquelas brincadeiras de passare tal que tem muito disso ainda. Mas é totalmente normal. A gente tem os horários para tomar o remédio, as responsabilidades são maiores, porque qualquer coisa assim... uma pessoa que está com gripe, se está perto da gente é perigoso, porque assim... com HIV, essa preocupação, de não ficar doente, tomar os remédios na hora certa, mas, fora isso é absolutamente normal. Vou ao shopping, cinema, vou passear, vou pro parque, vou pra praia, normal" (sexo feminino, 15 anos, transmissão vertical).

É claro que a relevância desses limites entre ser normal ou não sentir-se assim, faz do momento da revelação um ponto crítico nas suas biografias, e torna bastante importante o modo como se dá essa revelação.

\section{- Situações de revelação do diagnóstico}

A revelação da infecção pelo HIV torna-se o marco inicial para a construção de uma nova

\begin{tabular}{|c|c|c|}
\hline \multicolumn{3}{|c|}{$\begin{array}{l}\text { Perfil dos jovens entrevistados, segundo via } \\
\text { de transmissão do HIV, sexo e faixa etária. }\end{array}$} \\
\hline & \multicolumn{2}{|c|}{ Sexo } \\
\hline & Feminino & Masculino \\
\hline \multicolumn{3}{|c|}{ Via de infecção } \\
\hline Vertical & 8 & 5 \\
\hline Sexual & 3 & 3 \\
\hline Transfusão & 1 & - \\
\hline Ignorado & 1 & 2 \\
\hline \multicolumn{3}{|c|}{ Idade (em anos) } \\
\hline$\leq 14$ & 4 & 1 \\
\hline $15-16$ & 5 & 5 \\
\hline $17-20$ & 3 & 4 \\
\hline Total (n) & 12 & 10 \\
\hline
\end{tabular}

história e identidade. Nas entrevistas, investigou-se como os jovens foram informados sobre seu diagnóstico, suas vivências frente a esta comunicação, o impacto determinado em sua vida íntima e nas suas relações com a família, amigos, escola e trabalho.

Pode-se perceber diferenças no conjunto das entrevistas, com dois padrões de revelação do diagnóstico para os adolescentes. A comunicação do diagnóstico relatada pelos adolescentes que cresceram com o HIV (transmissão vertical) mostrou-se mais cercada de cuidados e preocupação com a sua repercussão sobre a vida desses jovens, ou seja, apresentou-se como assunto pensado e trabalhado por cuidadores e profissionais. Para os entrevistados que se infectaram pela via sexual ou que não sabem como se infectaram, em contraste, não se observou nenhum trabalho prévio ou cuidado com o assunto, com relatos de revelação diagnóstica mais rudes e descuidadas.

"O bom foi que meus tios me contaram tudo com objetividade e honestidade. A decisão de contar foi pela necessidade de explicar os medicamentos" (sexo feminino, 15 anos, transmissão vertical).

"Eu peguei, fui, fiz o exame, e depois de quinze dias fui buscar. Bonitinho, fui no laboratório que ficava aqui na... numa travessa da Av. Angélica. Fui, peguei o exame e, assim abri o exame.... a hora que eu abri deu reagente. Eu olhei 'Ups'. Aí tinha o segundo teste, que é o anexado. Abri ele: reagente. Foi um choque na hora. Entrei em estado de choque no meio da rua. Estava sozinho no meio-fio, sem passar nada pela cabeça. 
Descrição dos cuidadores e jovens e de aspectos da revelação do diagnóstico.

\begin{tabular}{|c|c|c|c|c|c|c|c|}
\hline Entrevista & Cuidador & $\begin{array}{l}\text { Idade } \\
\text { atual } \\
\text { (anos) }\end{array}$ & Sexo & $\begin{array}{l}\text { Idade na } \\
\text { revelação }\end{array}$ & $\begin{array}{l}\text { Quem/Local } \\
\text { da revelação }\end{array}$ & Motivo & Classificação da revelação \\
\hline 1 & Tia materna & 9 & $\mathrm{~F}$ & Recente & $\mathrm{Tia} / \mathrm{Casa}$ & $\begin{array}{l}\text { Antecipada devido } \\
\text { a perguntas da criança }\end{array}$ & Completa \\
\hline 2 & Mãe HIV+ & 15 & $\mathrm{~F}$ & Recente & Mãe/Serviço & $\begin{array}{l}\text { Tinha de saber para se } \\
\text { cuidar melhor }\end{array}$ & Completa \\
\hline 3 & Pai adotivo & 12 & $\mathrm{~F}$ & 11 & Pai/Na praia & $\begin{array}{l}\text { Gradual, antecipada devido } \\
\text { a perguntas da criança }\end{array}$ & Completa \\
\hline 4 & Coordenadora & $V^{*}$ & * & Gradual & $\begin{array}{l}\text { Voluntários; } \\
\text { equipe/Serviço }\end{array}$ & $\begin{array}{l}\text { Sem programação, em alguns } \\
\text { momentos é feito. Espera-se } \\
\text { uma estrutura mais dirigida }\end{array}$ & $\begin{array}{l}\text { Indeterminado-gradual. } \\
\text { Para os maiores: completa }\end{array}$ \\
\hline 5 & Avó paterna & 16 & $\mathrm{~F}$ & 10 & Avó/Casa & $\begin{array}{l}\text { Desencadeada por comentário } \\
\text { na clínica: "está aqui quem } \\
\text { tem AIDS" }\end{array}$ & Completa \\
\hline 6 & Mãe HIV- & 17 & M & 15 & Equipe/Serviço & Estava maduro, começou namoro & Completa \\
\hline 7 & Mãe HIV+ & 15 & $\mathrm{~F}$ & 14 & $\begin{array}{l}\text { Mãe/Durante } \\
\text { internação }\end{array}$ & $\begin{array}{l}\text { Mãe negação do diagnóstico até } \\
\text { há dois anos, revelou há quatro } \\
\text { meses, insistência dos médicos }\end{array}$ & Completa \\
\hline 8 & Tia materna & 12 & $\mathrm{~F}$ & Gradual & $\begin{array}{l}\text { Tia/Desde } \\
\text { pequena }\end{array}$ & Dizer a verdade sempre & Completa \\
\hline 9 & Mãe adotiva & 13 & M & $10 / 11$ & Médico/Serviço & $\begin{array}{l}\text { Recusa a tomar medicamentos. } \\
\text { Sabia ser adotado }\end{array}$ & Completa \\
\hline 10 & Mãe HIV+ & 10 & $\mathrm{~F}$ & Não & Mãe/Casa & $\begin{array}{l}\text { Ainda não está no momento e } \\
\text { como explicar como se infectou? }\end{array}$ & $\begin{array}{l}\text { Parcial. Segredo: } \\
\text { despistamento }\end{array}$ \\
\hline 11 & Coordenadora & * & * & Gradual & $\begin{array}{l}\text { Equipe/Casa } \\
\text { de apoio }\end{array}$ & Compõe o cenário de suas vidas & $\begin{array}{l}\text { Gradual. Para os maiores: } \\
\text { completa }\end{array}$ \\
\hline 12 & Mãe adotiva & 17 & M & 9 & $\begin{array}{l}\text { Médica/Serviço, } \\
\text { completada } \\
\text { pelos pais }\end{array}$ & $\begin{array}{l}\text { Revelação tumultuada devido } \\
\text { a postura inadequada de médica }\end{array}$ & Completa \\
\hline 13 & Avó paterna & 14 & M & Não & $\begin{array}{l}\text { Diagnóstico não } \\
\text { explicitado }\end{array}$ & $\begin{array}{l}\text { Avó acha difícil revelar. } \\
\text { Diz que vai a um serviço quando } \\
\text { freqüenta outro e que os remédios } \\
\text { são bons para muitas doenças }\end{array}$ & $\begin{array}{l}\text { Parcial. Segredo: } \\
\text { mentira/despistamento }\end{array}$ \\
\hline
\end{tabular}

* Diferentes idades e sexos dos jovens vivendo em instituições.

Na hora 'apaguei'. Fui levado para casa por um taxista que encontrou meu endereço em minha bolsa. Em casa, o porteiro me levou para o apartamento, abriu a porta e me deitou na cama. Ao acordar comecei a chorar. Foi um desespero" (sexo masculino, 19 anos, transmissão sexual).

Foi comum entre os adolescentes entrevistados a opinião de que a revelação deveria ser realizada o mais cedo possível, mas com cuidados, e que as informações deveriam ser claras e precisas e acompanhadas sempre de suporte familiar e profissional.

"Eu acho que é melhor desde pequena, pra ela crescer ciente do que tem... se minha filha nascer com a mesma doença, eu vou contar desde pequena, pra depois ela não crescer revoltada e botar a culpa em mim" (sexo feminino, 13 anos, transmissão vertical).

\section{- As dificuldades da revelação a terceiros}

O conhecimento do diagnóstico determina um novo questionamento: a quem contar? A revelação de sua condição constituiu importante fonte de dificuldades para os jovens, que se mostraram divididos quanto ao que fazer com esse segredo: livrar-se do seu peso, convivendo com os riscos de possíveis rejeições, ou suportá-lo e ter de se haver com os prejuízos dessa escolha. A família e a escola (professores e diretores) apareceram como os principais grupos identificados como parceiros do segredo.

"Só a família sabe, avó, irmã, bisavó (...). Tenho medo de que as pessoas se afastem de mim se souberem" (sexo feminino, 18 anos, transmissão sexual). 
"Os professores sabem, mas não quero contar aos amigos" (sexo masculino, 16 anos, transmissão vertical).

A revelação do diagnóstico aos parceiros afetivos e/ou sexuais adquire complexidade adicional. Se, por um lado, é reconhecida a necessidade de proteger o parceiro da possibilidade de infecção, por outro, revelar sua condição e ser abandonado apresenta-se como um acontecimento possível e bastante ameaçador. $O$ resultado costuma ser "deixar para mais tarde a decisão", com veremos mais adiante.

"Até os pirralhos hoje estão tendo relação sexual, mas não é a minha praia. Tem que ter cuidado, porque se você tem e você sabe... se você já não gosta, que dirá outra pessoa. Tem que ter cuidado, usar preservativo, porque o preservativo serve pra quê? (...) O namoro é bom, mas ele não sabe do meu problema, não pretendo contar tão cedo... porque preciso pegar confiança nele primeiro. Pra depois eu contar" (sexo feminino, 13 anos, transmissão vertical).

A ameaça, vivida ou introjetada, representada pela discriminação e o estigma reflete-se ainda na própria capacidade de fazer planos para o futuro. $\mathrm{O}$ adolescente às vezes restringe de antemão suas ambições, pelo medo da exclusão.

"Eu gosto mesmo é de computador. Eu ia fazer Ciência da Computação. Ah, eu acho que eu vou ter que... não sei, né? Se eles perguntar, por exemplo, pode até pedir o tipo de sangue, eu vou ter que contar, lógico..." (sexo masculino, 14 anos, transmissão vertical).

"Receio o quanto a discriminação pode atrapalhar minha carreira e minhas relações pessoais" (sexo feminino,14 anos, transmissão vertical).

\section{Entrevistas com cuidadores}

\section{- A revelação diagnóstica e os serviços de saúde}

Os relatos dos cuidadores permitiram identificar que as estratégias adotadas pelos serviços que cuidam de crianças e adolescentes vivendo com HIV/AIDS são muito diversificadas.

Uma primeira estratégia identificada é uma abordagem sistemática, com a composição de equipes e grupos de familiares (cuidadores) supervisionados, e a assistência individualizada a cada família. A proposta aqui parece residir fundamentalmente em fortalecer e fornecer recursos ao cuidador de modo a torná-lo capaz de fazer a revelação. Nestes casos, o serviço procura seguir uma rotina preestabelecida, ainda que outras estratégias opcionais sejam possí- veis, como a possibilidade dos cuidadores delegarem a tarefa da revelação à equipe de saúde.

Em contraste, encontramos também nos relatos propostas de decisões mais individualizadas, não apoiadas em rotinas de grupos de discussão. Nesse caso a revelação foi feita pelo cuidador ou pela equipe, a partir de discussões e decisões acordadas entre as partes.

Uma terceira situação encontrada foi aquela em que não foi possível perceber qualquer política pré-definida de abordagem para o tema. As situações aconteceram e se resolveram, segundo demanda espontânea ou conduta individual, como resposta a momentos específicos de dificuldade no atendimento ou no tratamento do jovem.

Outro aspecto que nos interessou identificar foi o cenário da revelação, isto é, quais foram as pessoas presentes no momento da revelação, onde ela se deu, como foi a dinâmica das interações entre os participantes etc. Aqui mais uma vez não houve um padrão homogêneo.

\section{- O processo da revelação}

Foi investigada a posição dos cuidadores no que diz respeito a cinco aspectos principais: a motivação para a revelação; a reação do jovem no momento da revelação; a sua reação posterior; a reação dos familiares; e a ampliação da revelação do diagnóstico a outros membros da família e da comunidade.

Foram identificadas três situações predominantes nos relatos dos cuidadores acerca da motivação para a abertura do diagnóstico para o jovem: (a) necessidade premente ou "imperiosa"; (b) convicção sobre o benefício da revelação; e (c) correção de uma intervenção profissional inadequada.

\section{a) Necessidade premente ou "imperiosa"}

Algumas situações relatadas pelos cuidadores apontaram para uma necessidade de contar aos jovens sobre a sua soropositividade que transcendeu qualquer tipo de decisão $a$ prio$r i$, refletida com tranqüilidade, mas impôs-se por razões que surpreenderam os cuidadores em sua busca de prover apoio e proteção. Essa necessidade pode decorrer do questionamento da criança acerca de sua doença. Os cuidadores temiam que ela descobrisse sozinha, como no exemplo abaixo, em que todos na família, com exceção de seu irmão de oito anos, já sabiam do diagnóstico da criança, e se temia que esse fato gerasse na criança (nove anos) uma reação de revolta ou sentimento de traição. 
"A decisão de revelar o diagnóstico foi antecipada por T., que perguntou que bichinho ela tinha? Porque tinha que tomar tanto remédio? Se ela sarar, até quando teria que tomar medicação?" (tia materna - sexo feminino, 9 anos, transmissão vertical).

Ou em outro caso, em que o pai adotivo já vinha recebendo orientação do serviço e a criança participando de grupo de preparo para revelação, mas, num dado momento, a família percebeu que não poderia mais adiar, mostrando a possibilidade de resolução da tarefa sem a intervenção direta da equipe.

“... quando ela era pequena a gente contava histórias, que tinha uns bichinhos na corrente sangüinea, que ela precisava tomar remédio para matar esses bichinhos. Então, sempre foi uma história conforme a idade. E aí a gente viu que estava chegando a hora de colocar para ela o que realmente tinha. [Ela] Tinha começado a questionar, começou a ler, ver na televisão e tal" (pai adotivo - sexo feminino, 12 anos, transmissão vertical).

Uma outra situação encontrada apontou para o problema da não adesão ao tratamento como um fator de precipitação da decisão de revelação pelo médico, durante uma consulta.

“... eu até discuti com o Dr. M. que o T. não estava tomando remédio nenhum, até que chegou uma hora que o Dr. M. disse assim: 'ó, eu não posso fazer mais nada, ele não quer tomar remédio nenhum'. Eu estava... ele estava sentado do meu lado assim: 'você é HIV'. Aí ele ficou parado assim, ele não abriu a boca, ele chorou, correu um pouco as lágrimas" (mãe adotiva sexo masculino, 13 anos, transmissão vertical).

Outra situação de premência para os cuidadores é a proximidade da vida sexual.

“... ele tava paquerando uma menina, que ele tava namorando, ai o Dr. S. e A. [enfermeira] falaram: 'agora você tem que falar, porque ele já tá namorando, tá ficando'..." (mãe soronegativa sexo masculino, 17 anos, transmissão por transfusão).

\section{b) Convicção sobre o benefício da revelação}

A motivação de contar sobre o diagnóstico também esteve associada, nos depoimentos, à percepção, seja por características próprias à dinâmica e à visão de vida da família, seja em função de um trabalho desenvolvido dentro de uma instituição, as casas de apoio, de que o segredo sobre a soropositividade limita as possibilidades da criança ou do adolescente de lidar de um modo positivo com a sua condição.

“... na verdade elas já cresceram sabendo, então não é nenhum choque, não é nenhuma novidade, contei pra P. desde pequenininha, então eu não sei se é por isso que ela tava nessa ótima, ela aceita numa boa, assim, ela sabe da medicação, ela sabe que ela tá precisando fazer um outro exame, pra ver, porque a carga viral dela tá muito alta, aceita numa boa, entendeu? Ela sabe que tem medicação, que é muito boa. Desde pequenininha... [?] ..não, não, eu sou contra, eu sou assim tem que falar a verdade, tem que crescer sabendo. Eu acho que tem que crescer sabendo pra não ter choque depois" (tia materna - sexo feminino, 12 anos, transmissão vertical).

O cuidador de uma casa de apoio foi entrevistado e revelou que optou por trabalhar o processo de revelação passo a passo, em todos os momentos, ajustando as informações e o modo de conversar à faixa etária das crianças e sua capacidade de compreensão, decidindo por não individualizar a abordagem - $\mathrm{o}$ assunto é tratado coletivamente, no cotidiano da casa, apoiado na ação de equipe multiprofissional.

" $E$ eu costumo sempre fazer assim, eu acho que a criança que é soropositiva, ela tem que ser... falar a cada passo. Todos os dias, em todos os momentos. Não é 'você é soropositiva', não é isso. É em todos os momentos que há oportunidade, é um jogo claro, limpo, verdadeiro. (...) Se você pegar os nossos adolescentes da casa de apoio, eles te dão uma aula de soropositivo, HIV, do que pega do que não pega, como que pega, o que passa o que não passa, o que eu posso, o que eu não posso" (cuidador institucional).

O responsável por outra instituição, quando entrevistado, referiu a não existência de uma estrutura organizada para discutir os aspectos da revelação e o assunto é tratado circunstancialmente, de forma esporádica, pois a coordenadora entende que a questão é difícil de ser incorporada na sua prática cotidiana.

“... na verdade os maiores que sabem. Foi através de psicólogo, através de 'tios'e 'tias' daqui e tal, que foi conversado. Mas, por exemplo, o P., quando foi contar para ele, ele não se interessou em saber, acho até porque o P. tem um problema de fala, acho que tem algum problema mental. É uma criança que não se interessou em saber. $O$ V., 'ah, quem me fez?', 'então a minha mãe também tinha?” (cuidador institucional).

\section{c) Correção de uma intervenção profissional inadequada}

As relações entre os profissionais de saúde e os cuidadores nem sempre se dão de forma harmônica, tranqüila. Houve situações em que a motivação dos cuidadores para falar sobre o assunto teve o objetivo de evitar danos maio- 
res devido a uma abertura diagnóstica pouco cuidadosa.

Em um dos relatos, a mãe adotiva relata que ela e seu marido já estavam se preparando para revelar o diagnóstico do HIV. O conhecimento sobre a sua adoção já havia sido inadequado e, por isso, estavam tomando especial cuidado para dar mais essa notícia ao filho. Foram, no entanto, surpreendidos pela postura inadequada de uma médica.

“Aí, eu peguei meu filho, fui tratar com meu filho no Hospital X. Lá tô eu diante de uma médica poderosa, que senta eu e meu filho na frente dela e um monte de estudantes e ela fala: 'mãe, aqui se trata de AIDS e AIDS mata', na frente do meu filho, foi assim que ele ficou sabendo" (mãe adotiva - sexo masculino, 17 anos, transmissão vertical).

Depois dessa ocorrência, a entrevistada foi para casa e, junto com o marido, conversaram com o menino.

"O meu filho não tinha sido preparado pra ouvir. Eu estava trabalhando, eu e o pai, para nós podermos estar bem pra contar pro menino. Como é que de repente, ela fala assim? E o menino fica assustado: 'mãe, eu vou morrer?'. Saiu de lá falando: 'eu vou morrer?' 'Eu vou morrer?"' (mãe adotiva - sexo masculino, 17 anos, transmissão vertical).

\section{- Reação do jovem à revelação}

Nos relatos colhidos acerca do momento da revelação, destaca-se a descrição de um primeiro momento em que a reação foi de choro moderado ou intenso, ou de completo e inquietante silêncio, seguido de uma reação à notícia caracterizada por perguntas sobre modo de aquisição, aspectos da doença, perspectivas futuras.

“Ah, foi meio pesado de falar pra ela, né? Triste, também. Revelamos, eu chorei, ela chorou... Chorou bastante, ficou um pouco sentida, mas... depois continuou normal" (mãe soropositiva - sexo feminino, 15 anos, transmissão vertical).

\section{Reação posterior do jovem}

Foi um relato bastante comum entre os entrevistados a referência a um efeito benéfico, a longo prazo, da revelação diagnóstica para o adolescente (ou a criança, a depender da época da revelação) vivendo com HIV. Esse efeito positivo é percebido pela melhoria do humor $\mathrm{e}$ da atitude, ou simplesmente por não ter causado impacto negativo sobre as atividades rotineiras do jovem. É muito valorizado o fato da revelação aumentar a possibilidade de dialogar.
Em alguns momentos, percebe-se a tristeza ou certo grau de inconformismo, mas a possibilidade de conversar sobre o assunto traz mais facilidade para oferecer conforto, auxiliar no exercício de assumir a própria doença e tratamento.

“... eu sinto que ajudou, ajuda. Com certeza hoje ela se cuida mais, é mais preocupada com relação aos remédios" (mãe soropositiva - sexo feminino, 15 anos, transmissão vertical).

"Tem hora que ele fica triste, ele fala assim: 'eu tomando essas merdas ou não tomando vou morrer do mesmo jeito'. Eu falo 'não, não é assim, você, se você tomar, você vai prolongar a tua vida, quem sabe amanhã, sai a cura dessa doença"' (mãe adotiva - sexo masculino, 13 anos, transmissão vertical).

\section{- Reações dos cuidadores e familiares}

A possibilidade de que a revelação da infecção à criança ou adolescente possa implicar a revelação da própria infecção ou de outros aspectos biográficos delicados ou estigmatizados na família ou na sua história (tais como uso de drogas, homossexualidade etc.) surgiu como uma dificuldade importante para cuidadores e famílias, antes e após a revelação.

"Ela vai perguntar: 'mas como que eu peguei?' Aí eu vou ter que falar que foi de mim. Como que eu vou explicar pra ela que eu peguei? $E$ complicado. Fala se não é?" (mãe soropositiva sexo feminino, 10 anos, transmissão vertical).

Quando a revelação é realizada, a principal manifestação dos entrevistados quanto ao impacto da revelação foi de alívio, e entre as razões apontadas para isso destaca-se a facilitação do diálogo.

"Foi muito bom ela ter perguntado, me deu oportunidade de falar, eu odeio ter que esconder as coisas, agora a gente está feliz. Antes eu vivia irritada, nervosa, cansada, agora estou sossegada, tirei um peso de dentro de mim. (...) No começo a revelação parecia um bicho de sete cabeças, porém é possivel a gente matar o monstro" (tia materna - sexo feminino, 9 anos, transmissão vertical).

\section{- A revelação do diagnóstico para terceiros}

Entre os casos estudados, observou-se uma certa restrição do círculo de pessoas que sabem do diagnóstico do jovem, mesmo no que se refere a outros membros do núcleo familiar, como as crianças mais novas. Entre os entrevistados foi comum o relato de que outros familiares conhecem a condição de infectado da 
criança, mas com uma tendência de restringir a revelação quando se trata de amigos e/ou vizinhos.

Quanto à escola, encontramos posturas variáveis. Em uma mesma família há relato de revelação em uma escola, mas não para uma segunda, na qual a criança foi matriculada mais recentemente. A maioria das famílias está orientada acerca dos riscos e condutas frente à discriminação na escola. Descreve-se, em geral, uma razoável aceitação no ambiente escolar e o compromisso dos professores de ministrar os medicamentos, tolerar faltas e restrições da criança, como por exemplo, não freqüentar as aulas de educação física, quando recomendado etc. Houve situação em que os profissionais dos serviços de saúde foram à escola para esclarecer os professores.

Essas ampliações da revelação são relatadas, em geral, como experiências bastante delicadas, difíceis. O medo do preconceito é um limitante importante, e muitas vezes este deixa de ser apenas um receio. Há, com efeito, relatos de discriminação importante, mesmo entre familiares e amigos.

“...que nem os meus vizinhos, meus, não sabem, porque duas vizinhas eu fui tentar falar e... 'ai, Deus o livre, essa doença?! Ai... nem piso no quintal!'. Aí eu comigo, né, 'ai coitada, né, se ela souber que o filho dela vive grudado com o meu brincando.... Então eu falo que ele tem leucemia. E quando ele ficou sabendo da doença dele eu falei: 'ó $X$., se você quiser falar a verdade eu tô aqui, eu te peguei quando você era nenê, eu brigo agora por vocế. E ele falou assim que ele também não quer falar porque ele tem medo do preconceito" (mãe adotiva - sexo masculino, 13 anos, transmissão vertical).

\section{Discussão}

A revelação do diagnóstico apresenta-se como um momento especial no processo de atenção à saúde de crianças e adolescentes infectados pelo HIV e suas famílias. A revelação mostra-se um elemento essencial para a elaboração e planejamento do seguimento, proporcionando referenciais de evolução e prognóstico, permitindo-se interferir ativamente sobre aspectos evitáveis da vulnerabilidade desses pacientes ao adoecimento ou sofrimento desnecessário.

A revelação assume particularidades quando pensada a partir do ponto de vista dos pacientes e dos cuidadores, apesar de ser reconhecida como fundamental por ambos.

Para o profissional, permite que a organização e programação das condutas sejam discu- tidas com seu paciente e cuidadores de maneira clara, sem ter de administrar um segredo, que, na maior parte das vezes, determina entraves em sua relação com pacientes e famílias.

Para os jovens, a revelação de seu diagnóstico possibilita-lhes recolocar-se frente a uma nova realidade, fazendo escolhas e tomando decisões dentro de alternativas reais, com a autonomia e controle possíveis. A adesão ao tratamento e atitudes responsáveis em relação a si mesmos e seus parceiros estão diretamente relacionadas à comunicação adequada entre os pacientes, suas famílias e cuidadores e os profissionais de saúde 20 .

Do ponto de vista dos pais e cuidadores, a revelação do diagnóstico é reconhecida como necessária, irremediável e um desafio a ser enfrentado. A manutenção do segredo é desconfortável, freqüentemente angustiante 21,22,23.

É importante que os serviços de atendimento a crianças e adolescentes infectados pelo HIV estabeleçam e aprimorem claramente uma política de revelação de diagnóstico, incluindo os jovens infectados já na adolescência, por transmissão sexual ou uso de drogas, para os quais foi mais comum, em nossa investigação, encontrar relatos de experiências problemáticas. Esse momento deve fazer parte do planejamento dos cuidados oferecidos a eles e seus cuidadores. Por isso, a principal recomendação para a melhoria do cuidado dirigido aos adolescentes vivendo com HIV/AIDS, sugerida com base no estudo, é que se busque a ativa inclusão deste aspecto no planejamento rotineiro das ações de atenção à saúde. Para que isso ocorra de modo efetivo e adequado, é preciso, também, que se estabeleça um processo contínuo de discussão envolvendo cuidadores e equipe multiprofissional a respeito dos critérios que cada família adotará para eleger qual o melhor momento e maneira de efetuar a revelação 24,25 . Essa tarefa deve ser encarada como um processo a ser desenvolvido com o envolvimento simultâneo de cuidadores e profissionais, levando em conta cada adolescente, as particularidades de seu contexto social, doméstico, seu sexo e faixa etária.

Tanto os cuidadores como as equipes de saúde devem estar integradas na tarefa, entretanto, os depoimentos não sugerem um perfil profissional específico mais apropriado para conduzir o processo de revelação. É importante identificar os vínculos mais significativos para os pacientes e utilizá-los como referência para o planejamento das intervenções.

É extremamente importante que equipe e cuidadores estejam, por sua vez, alertas para o fato de que a comunicação do diagnóstico de- 
termina a exposição do paciente a fatos e particularidades de sua história familiar e que esta é também questão a ser trabalhada com a família e com o adolescente, e acompanhada, tanto quanto os efeitos da revelação em si mesma. Essa exposição pode requerer um amplo conjunto de suportes psicossociais a serem oferecidos.

Foi também um achado muito expressivo em nosso estudo, a importância dada pelos adolescentes que entrevistamos de que as informações a eles transmitidas sejam claras e precisas, que se use uma linguagem apropriada incluindo dados detalhados e concretos sobre sexo mais seguro e todas as dimensões da prevenção da infecção.

Finalmente, é importante destacar que nesta pesquisa foram relatados vários sentimentos e experiências de estigma e discriminação pelos jovens e seus cuidadores, as quais ocorreram nas suas vivências em família, na vizinhança, na escola, no trabalho e nos serviços de saúde. Muitos dos entrevistados revelaram que sentiram e vivenciaram o estigma no momento exato em que descobriram seu diagnóstico. A despeito de todos os avanços no diagnóstico e tratamento, ainda persiste a idéia de AIDS como morte, seja física ou dos projetos de futuro e felicidade, o que tende a afastar o jovem e seus cuidadores do usufruto da sua vida pessoal e social, produzindo enorme dano e sofrimento. Assim, deve-se continuar e ampliar o debate acerca do estigma e discriminação relacionados à infecção pelo HIV, recusando-se ativamente toda exclusão ou restrição baseada no estado sorológico.

\section{Resumo}

O objetivo deste estudo foi identificar aspectos da revelação do diagnóstico da infecção pelo HIV a crianças e adolescentes relevantes para a melhoria do cuidado de sua saúde. Trata-se de estudo qualitativo envolvendo entrevistas em profundidade e grupo focal com adolescentes vivendo com HIVIAIDS e seus pais ou cuidadores, em serviços de referência nas cidades de São Paulo e Santos, Brasil. Os resultados apontam como principais razões para a revelação: má adesão ao tratamento, iminência de início da vida sexual, demanda da crianç ou adolescente e abordagem inadequada de profissional. A revelação mostrou-se momento crítico, com repercussões sobre projetos e horizontes de vida dos adolescentes. As mais problemáti-

\section{Conclusões}

Deve-se cuidar ativa e atentamente do processo de revelação do diagnóstico às crianças e adolescentes infectados pelo HIV, destacando que atenção especial deve ser dada aos que se infectaram mais velhos, por transmissão sexual ou por uso de drogas, visto que pode haver risco, nessas situações, de que sejam subestimadas as necessidades de acolhimento e cuidado necessitados pelos jovens, com graves repercussões sobre sua saúde e qualidade de vida. Há que se observar e apoiar ativamente o adolescente após a revelação para os possíveis conflitos e dificuldades que possam surgir da revelação. Outra necessidade apontada pelo estudo é o ativo combate ao estigma. Trabalhar esse aspecto nos serviços de saúde pode ser um dos caminhos para a redução, ao menos, de seus impactos. Facilitar a discussão e troca de vivências, aproveitar todas as oportunidades cotidianas de contato para criar vínculos e desenvolver estratégias educativas específicas para o adolescente com informações claras, objetivas e científicas também se mostra essencial, inclusive para a redução do estigma.

Em todos esses aspectos, o recurso aos direitos humanos pode ser produtivo, seja na perspectiva de criar atividades nos serviços de saúde que ajudem os adolescentes a identificar e superar desnecessárias restrições, externas ou internas, em seus planos e expectativas, seja na possibilidade que aponta para o estabelecimento de ações e programas intersetoriais, capazes de melhorar o cuidado oferecido 25 , fazendo da revelação diagnóstica um passo produtivo no sentido não apenas do controle da infecção, mas também da promoção da saúde.

cas foram narradas por adolescentes infectados por via sexual e por uso de drogas. Apesar do impacto negativo inicial, a revelação repercutiu positivamente sobre os cuidados de saúde, com melhoria do diálogo com cuidadores e serviços. Os adolescentes enfatizaram ainda a necessidade de receber informações claras e honestas. Conclui-se pela necessidade de otimizar o processo de revelação, tratando-o como tarefa de longo prazo, negociada ativamente com a família e conduzida por equipes multidisciplinares.

Adolescentes; Síndrome de Imunodeficiência Adquirida; Diagnóstico Clínico 


\section{Colaboradores}

Os autores participaram ativamente de todas as fases do estudo. H. H. S. Marques na revisão da literatura, desenho do estudo, análise das entrevistas, discussão dos resultados e redação final do artigo. N. G. Silva, P. L. Gutierrez e R. Lacerda na revisão da literatura, desenho do estudo, trabalho e supervisão do campo, análise das entrevistas e grupos focais, discussão dos resultados, redação e revisão do artigo. J. R. C. M. Ayres foi o coordenador do projeto, participou da revisão da literatura, desenho do estudo, trabalho e su-

\section{Referências}

1. Eiser C. Growing up with a chronic disease. London: Jessica Kingsley; 1993.

2. Programa Nacional de DST/AIDS, Ministério da Saúde. Boletim Epidemiológico AIDS 2003; ano XVII, n. 1. http://www.aids.gov.br/final/biblioteca/boletim_dezembro_2003/index.asp (acessado em 01/Jun/2005).

3. Matida LH, Marcopito LF. O aumento do tempo de sobrevida das crianças com aids - Brasil. Boletim Epidemiológico AIDS 2002; ano XV, n. 2. http://www.aids.gov.br/final/biblioteca/bol_mar co_2002/artigo2.htm (acessado em 01/Jun/2005).

4. Melvin D, Sherr L. HIV infection in London children: psychosocial complexity and emotional burden. Child Care Health Dev 1995; 21:405-12.

5. Wiener LS, Battles HB, Heilman NE. Factors associated with parents' decision to disclose their HIV diagnosis to their children. Child Welfare 1998; 77:115-35.

6. Lee CL, Johann-Liang R. Disclosure of the diagnosis of HIV/AIDS to children born of HIV-infected mothers. AIDS Patient Care STDS 1996; 13:41-5.

7. Hoffman ND, Futterman D, Myerson A. Treatment issues for HIV-positive adolescents. AIDS Clin Care 1999; 11:17-9, 21, 23-4 concl.

8. Battles HB, Wiener LS. From adolescence through young adulthood psychosocial adjustment with long-term survival of HIV. J Adolesc Health 2002; 30:161-8.

9. Moreira MCN, Cunha CC. Repensando as práticas e dilemas no cotidiano de atenção à saúde de crianças e jovens vivendo com HIV/AIDS. Divulg Saúde Debate 2003; 29:73-92.

10. Harvard School of Public Health. ECI - Enhancing Care Initiative. http://www.eci.harvard.edu (acessado em 01/Jun/2005).

11. Denzin NK, Lincoln YS, editors. Handbook of qualitative research. Thousand Oaks: Sage Publications; 1994.

12. Minayo MCS. O desafio do conhecimento: pesquisa qualitativa em saúde. São Paulo: Editora Hucitec/Rio de Janeiro: ABRASCO; 2000.

13. Ricoeur P. Teoria da interpretação. Lisboa: Edições 70; 1996.

14. Gadamer HG. Verdad y método: fundamentos de una hermenêutica filosófica. Salamanca: Ediciones Sígueme; 1996.

15. Mann J, Tarantola D. From epidemiology, to vulnerability, to human rights. In: Mann J, Tarantola pervisão do campo, análise das entrevistas, discussão dos resultados e redação e revisão do artigo. M. DellaNegra, E. Galano, A. A. C. Segurado e M. H. Silva na revisão da literatura, desenho do estudo, análise das entrevistas, discussão dos resultados e revisão do artigo. I. França Jr. e V. Paiva na revisão da literatura, desenho do estudo, trabalho de campo, análise das entrevistas, discussão dos resultados e revisão do artigo. V. Paiva também atuou na supervisão do campo.

D, editors. AIDS in the World II. New York: Oxford University Press; 1996. p. 427-76.

16. Ayres JRCM, França Jr. I, Calazans GJ, Saletti Filho HC. O conceito de vulnerabilidade e as práticas de saúde: novas perspectivas e desafios. In: Czeresnia D, Freitas CM, organizadores. Promoção da saúde: conceitos, reflexões, tendências. Rio de Janeiro: Editora Fiocruz; 2003. p. 117-39.

17. Gruskin S, Tarantola D. Health and human rights. In: Detels R, Beaglehole R, editors. Oxford textbook on public health. New York: Oxford University Press; 2001.

18. Gruskin S, Hendriks A, Tomasevski K. Human rights and responses to HIV/AIDS. In: Mann J, Tarantola DJM, editors. AIDS in the world II. New York: Oxford University Press; 1996. p. 326-40.

19. Franca Jr. I, Ayres JRCM. Saúde pública e direitos humanos. In: Fortes PAC, Zoboli ELCP, organizadores. Bioética e saúde pública. São Paulo: Centro Universitário São Camilo/Edições Loyola; 2003. p. 63-9.

20. Oleske JM, Huben-Hale A; Supportive Care Quality of Life Committee. Enhancing supportive care and promoting quality of life. Bethesda: National Institute of Allergy and Infectious Diseases; 1994.

21. Gerson AC, Joyner M, Fosarelli P, Butz A, Wissow L, Lee S, et al. Disclosure of HIV diagnosis to children: when, where, why and how. J Pediatr Health Care 2001; 15:161-7.

22. Lyon ME, D'Angelo LJ. Parental disclosure of HIV status. J Pediatr Hematol Oncol 2001; 23:148-50.

23. Figueiredo RM, Turato ER. Needs for assistance and emotional aspects of caregiving reported by AIDS patient caregivers in a day-care unit in Brazil. Issues Ment Health Nurs 2001; 22:633-43.

24. Instone SL. Perceptions of children with HIV infection when not told for so long: implications for diagnosis disclosure. J Pediatr Health Care 2000; 14:235-43.

25. Silva CRC. Criança e aids: ensaios e experiências. São Paulo: Núcleo de Estudos para Prevenção da AIDS; 1999.

26. Ayres JRCM, coordenador. Adolescentes e jovens vivendo com HIV/AIDS: cuidado e promoção da saúde no cotidiano da equipe multiprofissional. São Paulo: Enhancing Care Initiative; 2004.

Recebido em 19/Jan/2005

Versão final reapresentada em 05/Jul/2005 Aprovado em 12/Ago/2005 